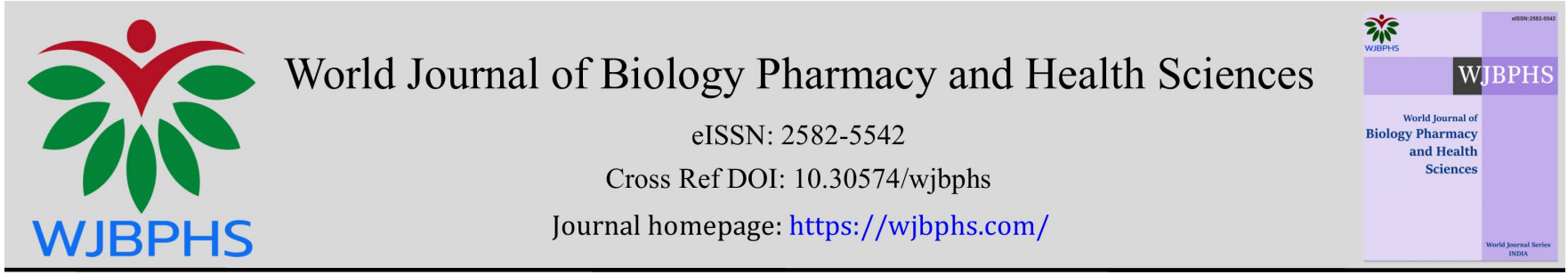

(RESEARCH ARTiCLE)

\title{
Influence of age, body mass index and waist-hip ratio on the human spine; a radiographic study of adult male subjects in Port Harcourt-Nigeria
}

\author{
Micheal Omonnkheoa Oyakhire 1, Loveday Ese Oghenemavwe 1, ${ }^{*}$ and Chukuemeka Emmanuel Agi 2 \\ ${ }^{1}$ Department of Anatomy, Faculty of Basic Medical Sciences, University of Port Harcourt. \\ 2 Department of Radiology, University of Port Harcourt Teaching Hospital.
}

World Journal of Biology Pharmacy and Health Sciences, 2021, 08(02), 001-007

Publication history: Received on 06 October 2021; revised on 01 November 2021; accepted on 03 November 2021

Article DOI: https://doi.org/10.30574/wjbphs.2021.8.2.0110

\begin{abstract}
The study determined the Lumbosacral angle (LSA) of male subjects and evaluated its relationship to age, BMI and Waist -Hip ratio. Lateral radiographs of one hundred and forty-two informed healthy male volunteers between the age of 1860 were studied using Ferguson's method, and analyzed with respect to age, waist hip ratio (WHR) and body mass index (BMI).. The result showed the average value for Lumbosacral angle was $34.06^{0} \pm 0.56^{0}$, the body weight was $70.34 \pm$ $1.02 \mathrm{Kg}$, and BMI was $24.64 \pm 0.38 \mathrm{Kgm}^{-2}$. Angle values were observed to increase with age up to 32years, followed by a sinusoidal increase and decrease pattern thereafter. Significant correlations were observed between LSA and Body weight as well as between LSA and BMI $(\mathrm{p}<0.05)$. The Lumbosacral angle of males in Port-Harcourt, South South Nigeria is within the range of literature derived measurement values world-wide, but lower than the average reported from previous studies on other Nigerian populations.
\end{abstract}

Keywords: Lumbosacral angle; BMI; Waist to Hip ratio; Ferguson's method; Port Harcourt; Spine

\section{Introduction}

The normal human spine has an S shape curve when viewed from the side [see figure 1] and the point of angulation between the sacrum and lumbar spines is the lumbosacral angle. The lumbosacral angle is a spine measurement derived from the wedge angle formed when the horizontal base of the angle is parallel to the ground level and the hypotenuse of the angle is formed at the level of the superior border of the sacrum. The plane of the sacrum forms the base from which the lumbar spine takes off in its ascent and by which it achieves its balanced state a [1, 2, 3].

High values of BMI have been reported to be associated with exaggerated lumbar curves and low back pain $[3,4,5,6,7$, 8]. On the contrary Youdas [9] and Noh, [10] reported there was no significant relationship between BMI and LSA. In a previous research, Mi-Yeon [7] did a across-sectional evaluation of 44 females between 21-45 years, with a mean age of 30 years, and reported a significant correlation between BMI and lumbar lordotic angle, lumbosacral angle and lumbar gravity line. In a related study Sibani [11] did not find any significant correlation between WHR and lumbar Lordosis.

In the healthy spine, specific arrangements of the wedge angles result in the regional curves and this enables the spine provide resilience and enables successive vertebrae bear and transfer weight of magnitude three times that which is attainable for a straight column. [1, 12, 13, 14] It has been suggested that in patients presenting with non-specific back pain, considerable distortion in the size and orientation of lumbosacral angle occurs. $[15,16,17]$ In the study by Silva, [18] lower back pain was observed to be etiologically related to increase in the LSA in as high as 75\% of cases. Other authors have also suggested that physical examination of patients presenting with spine problems yield best results when combined with radiographic assessment. [12, 19, 20, 21, 22, 23] The current study aimed to provide country

\footnotetext{
* Corresponding author: Loveday Ese Oghenemavwe

Department of Anatomy, Faculty of Basic Medical Sciences, University of Port Harcourt.
}

Copyright (C) 2021 Author(s) retain the copyright of this article. This article is published under the terms of the Creative Commons Attribution Liscense 4.0. 
normal values of the LSA of the spine for healthy adult male Nigerians, and to find out the influence of age and body indices on these normal values.

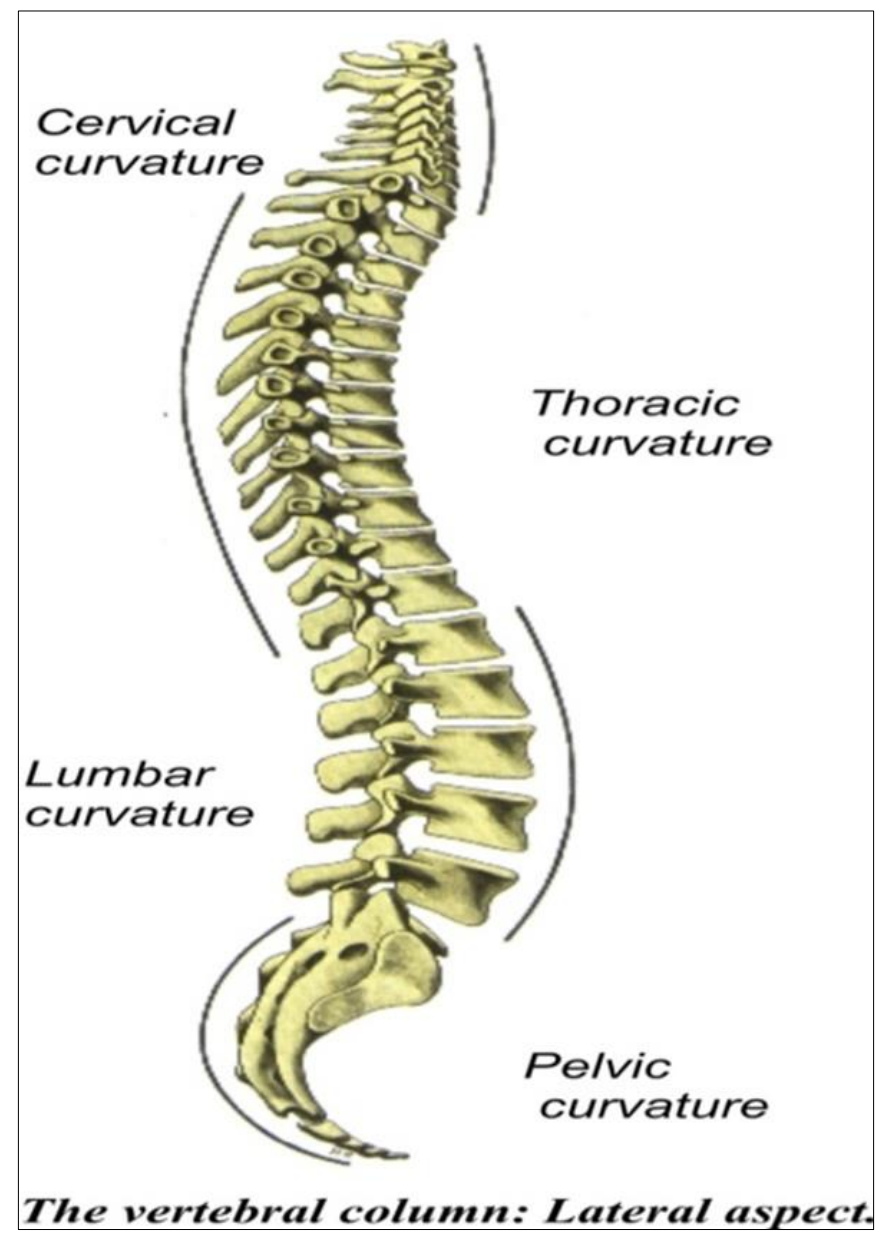

Figure 1 Diagram of the vertebral column and main regional curves. Derived from Sandring[1]

Approval was obtained from the Ethics Review Committee of the Faculty of Basic Medical Sciences, College of Health Sciences, of the University of Port Harcourt. The study sample comprised one hundred and forty-two (142) healthy male volunteers aged 18-60 who met the inclusion criteria and voluntarily gave informed consent.

Participants were required to be Nigerians with no medical records of musculoskeletal disease, resident in the South South geopolitical zone, and mentally fit to sign the informed consent form provided. Volunteers were properly and adequately informed about the nature, risks, benefits and confidentiality of the study. Subjects with medical history of $\mathrm{X}$-ray done one month prior to the current study, as well as those with radiographic evidence of scoliosis, kyphosis, degenerative changes such as spondylosis, presence of osteophytes or disc space narrowing were excluded from the study.

The study was conducted in three well designated centers in Port Harcourt; The radiology department of the University of Port Harcourt Teaching Hospital, Image Diagnostics center, Rumuola Port Harcourt. Ashford and Patrice Clinic LTD, D-line. These are located in Port Harcourt, a large multiethnic city in Nigeria

A film plate of $35 \times 43 \mathrm{~cm}$ was used for the lumbosacral spine, with a minimum subject image distance of $100 \mathrm{~cm}$.

\subsection{Sampling and Sample size}

The convenience sampling method was employed and the participants recruited through phone conversations, direct communication during health talks and conferences as well as by use of posters and radio. The minimum sample size was determined using formula provided by Portney and Watkins ${ }^{[29]}$, Lehana ${ }^{[30]}$ and European Commission. ${ }^{[31]}$ and a total of 142 subjects were used for the study 


\subsection{Measurement Techniques}

The Ferguson's method was used to evaluate the lumbosacral angle. The five lumbar vertebrae (L1-L5) were examined and the two end plates (superior and inferior) noted. The first sacral Vertebra (S1) was carefully identified and it's end plate (SEP) noted. On a transparency paper, a line (CD) was drawn horizontal and parallel to the edge of the table, and a second line (AB) drawn through and parallel to the superior end plate (sacral base) of the sacrum, the two lines were extended to their point of intersection, which technically is the fulcrum, at the lumbosacral articulation [See figures $2 \mathrm{a}$ and b]

The fulcrum of the transparent goniometer was positioned to align with that of the joint and the lumbosacral angle is the angle between lines B and D as shown in figures 2 and 3 above, being read from the $360^{\circ}$ protractor fixed on the Goniometer. Data were analyzed using SPSS version 17.0 (SPSS Inc., Chicago, IL.).
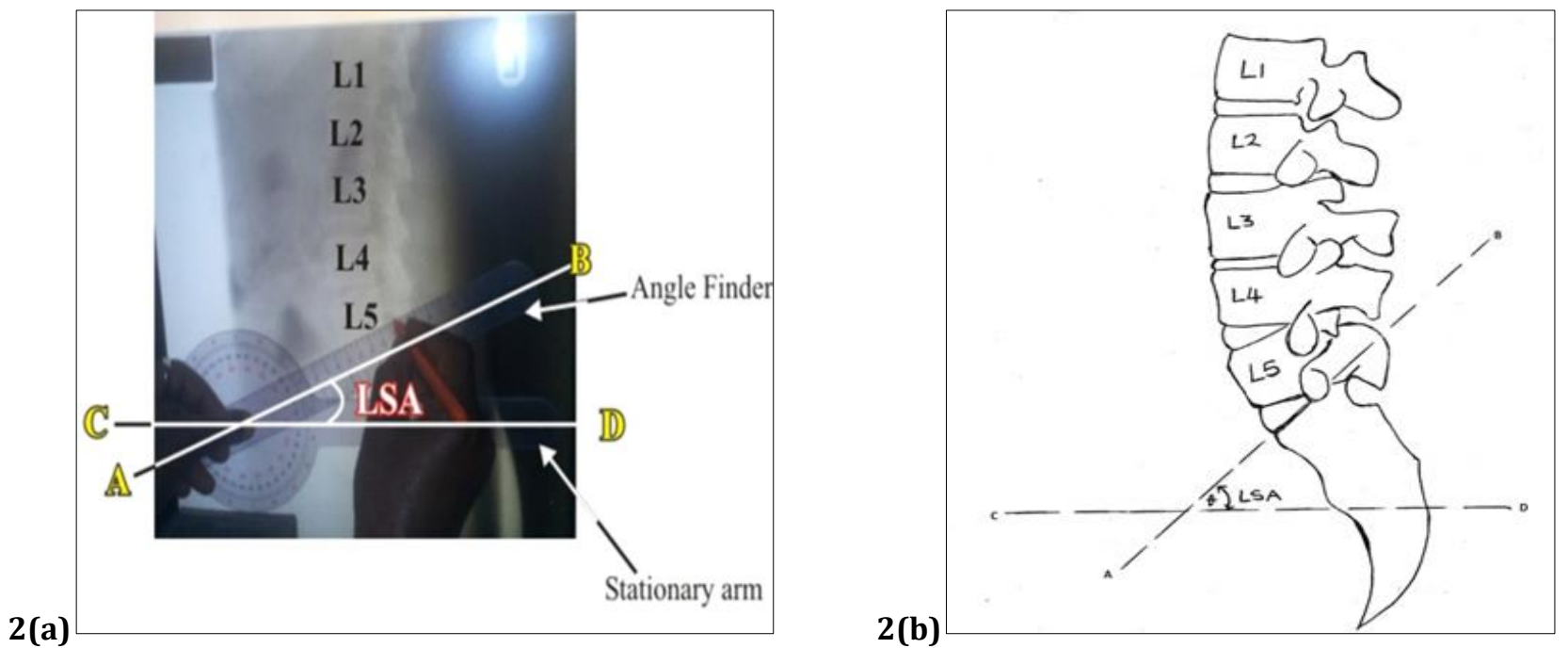

Figure 2(a)-(b) Measurement of Lumboscaral angle (LSA)

AB: A line drawn through and parallel to the superior end plate of the sacrum; CD: A line drawn horizontal and parallel to the edge of the table; LSA: lumbosacral angle

\section{Results}

The results are as presented below as Range, Mean and Standard Error [Table 1], comparison test (t-test for unpaired data) was also carried out [Table 2] as well as Pearson's correlation analysis [Table 3]

Table 1 Distribution of LSA by age groups

\begin{tabular}{|c|c|c|c|c|}
\hline Age groups & $\mathbf{N}$ & Range & Mean LSA $\mathbf{~}^{\circ}$ ) & Standard Error \\
\hline 18-22yrs & 31 & $24-45$ & 31.53 & 1.43 \\
\hline 23-27yrs & 24 & $23-37$ & 29.86 & 0.66 \\
\hline 28-32yrs & 18 & $22-36$ & 30.00 & 1.36 \\
\hline 33-37yrs & 20 & $24-27$ & 25.67 & 0.88 \\
\hline 38-42yrs & 23 & $25-35$ & 30.38 & 0.88 \\
\hline >42yrs & 26 & $34-38$ & 35.6 & 0.81 \\
\hline Total & 142 & $22-45$ & 30.56 & 0.5 \\
\hline
\end{tabular}

The highest value of LSA was observed in subjects older than 42 years, whereas the lowest observed mean LSA occurred in age class 23-27 years. 
Table 2 Independent sample t test, comparing LSA between the different age groups

\begin{tabular}{|c|c|c|c|c|c|}
\hline \multicolumn{2}{|c|}{ Age groups } & Mean diff & t-value & p-value & Inference \\
\hline \multirow{4}{*}{$18-22$} & $23-27$ & 1.67 & 1.2 & 0.24 & NS \\
\cline { 2 - 6 } & $28-32$ & 1.53 & 0.69 & 0.5 & NS \\
\cline { 2 - 6 } & $33-37$ & 5.86 & 1.68 & 0.11 & NS \\
\cline { 2 - 6 } & $38-42$ & 1.14 & 0.63 & 0.53 & NS \\
\cline { 2 - 6 } & $>42$ & -4.07 & -1.5 & 0.15 & NS \\
\hline \multirow{5}{*}{$23-27$} & $28-32$ & -0.14 & -0.1 & 0.92 & NS \\
\cline { 2 - 6 } & $33-37$ & 4.19 & 2.03 & 0.05 & NS \\
\cline { 2 - 6 } & $38-42$ & -0.53 & -0.46 & 0.65 & NS \\
\cline { 2 - 6 } & $>42$ & -5.74 & -3.56 & 0.00 & S \\
\hline \multirow{3}{*}{$28-32$} & $33-37$ & 4.33 & 1.75 & 0.11 & NS \\
\cline { 2 - 6 } & $38-42$ & -0.38 & -0.25 & 0.81 & NS \\
\cline { 2 - 6 } & $>42$ & -5.6 & -2.87 & 0.01 & S \\
\hline \multirow{3}{*}{$33-37$} & $38-42$ & -4.72 & -2.46 & 0.03 & S \\
\cline { 2 - 6 } & $>42$ & -9.93 & -7.88 & 0.00 & S \\
\hline $38-42$ & $>42$ & -5.22 & -3.42 & 0.00 & S \\
\hline
\end{tabular}

NS= Not significant; $S$ = Significant; Statistically significant differences were observed among various age groups as shown in the table above $(p<0.05)$.

Table 3 Pearson Correlation analysis

\begin{tabular}{|c|l|c|c|c|}
\hline \multirow{2}{*}{ Variables } & \multicolumn{3}{|c|}{ Pearson Correlation } \\
\cline { 3 - 5 } & R & P value & Inference \\
\hline \multirow{4}{*}{ LSA } & Age & 0.16 & 0.06 & NS \\
\cline { 2 - 5 } & Weight & 0.37 & 0.00 & S \\
\cline { 2 - 5 } & WHR & -0.10 & 0.22 & NS \\
\cline { 2 - 5 } & BMI & 0.32 & 0.00 & S \\
\hline
\end{tabular}

LSA also showed significant correlation with BMI and body weight respectively $(\mathrm{p}<0.05)$

\section{Discussion}

The purpose of this study was to determine normal reference values of the lumbosacral angles of healthy adult male Nigerians and find out if a significant relationship exists between the size of the angle and specific anthropometric characteristics such as Age, WHR and BMI.

We observed a nonlinear relationship between LSA and age of subjects. This is in line with previous reports [1,12,15] suggesting that among other factors, vertebral column morphology may be influenced by certain others which are unique to individuals.

Peleg et al. [14] via analysis of the sacral orientation angle, and using a method similar to those employed by Bogduk, [12] Cailliet, [19] Yochum and Rowe [22] reported that LSA first increases with advancing age and then falls around age 21-40 years. Also Kyu-Bok Kang et al. [27] analyzed changes of Sagittal Spinopelvic parameters in normal Koreans aged $50 y e a r s$ and over; mean sacral slope was $37^{0}$ with a range of $21^{0}-51^{0}$. 
Other investigators $[12,19,22,23,28,29,30]$ argued that range $25-57^{\circ}$ should be used as normal reference values for Caucasians. However Kim [18], in a more recent study recommended 30-40 to be used as reference values. Our findings are similar to those of Legaye, [31] Monister et al. [13] and Maduforo et al. [32]. The higher LSA values in males as observed by Mdufuro [32] could be as a result of differences in methodology, as subjects were older compared to those of the current study. Similarly in the study by Okpala [33] the distinction between the lumbosacral angle and lumbar lordosis angle with regards to the measurement technique applied was not made. In this study, we found a significant correlation with BMI but not with WHR. This is in agreement with other studies. $[4,7,33,34,35,36]$

\section{Conclusion}

This study showed that LSA of males in Southern Nigeria increases with advancing age up to the age of 32, followed thereafter by a sinusoidal increase and decrease pattern. We also established that in non-obese males, spinal health can be influenced significantly by BMI and not so by the WHR. These findings will be helpful in the planning and design of interventions aimed at restoring the normal size and shape of the lower spine in patients of different age and body indices.

\section{Compliance with ethical standards}

\section{Acknowledgments}

We acknowledged the contributions of the staff of Radiology Department of the University of Port Harcourt Teaching Hospital, Image Diagnostic Centre Port Harcourt, and Ashford and Patrice Clinics Port Harcourt for creating a friendly environment for the volunteers.

\section{Disclosure of conflict of interest}

The authors (Dr Micheal O. Oyakhire, Dr Loveday E. Oghenemavwe, Dr Chukwuemeka E. Agi) declare no conflict of interest.

\section{Statement of informed consent}

All participants were adequately prepared for the study; were given health education, all necessary information provided and voluntarily signed consent form.

\section{References}

[1] Sandring S. Grays anatomy: The anatomical basis of clinical practice. (3rd ed.). London (UK): Elsevier, Churchill Livingstone. 2005; 743-752.

[2] Levangie PL, Norkin CC. Joint Structure and Function, A comprehensive Analysis. (4th ed.)., Philadelphia USA. FA Davis Company. 2005; 170-174.

[3] Moore KL, Dalley AF. Clinically oriented anatomy, (5th edition), Lippincott Williams and Wilkins USA. 2006; 478, 489-490, 516.

[4] Hoseinfar M, Ghiasi F, Akbari A. The Relationship between Lumbar and Thoracic Curves with Body Mass Index and Low Back Pain in Students of Zahedan University of Medical Sciences. Journal of Medical Sciences. 2007; 7: 984-990.

[5] Murie VL, Dixon AK, Hollinworth W, Wilson H, Doylce TAC. Lumbar lordosis: study of patients with and without low back pain. Clinical Anatomy. 2003; 16(2): 144-147.

[6] Luike M, Solovieva S, Lamminen A, Luoma, K, Lein-Arjas P. Riihmäki H. Disc degeneration of the lumbar spine in relation to overweight. International Journal of Obesity (London). 2005; 29(8): 903-908.

[7] Mi-Yeon S, Won-Suk S, Sungsoo SC, Kim HS. Correlation between Obesity and Lumbar Lordosis in Obese PreMenopausal Korean Females. Korean Journal of Oriental Medicine. 2004; 25(4): 43-50.

[8] Meakin JRJ, Gregory JS, Aspden RM, Smith FW, Gilbert FJ. The intrinsic shape of the human lumbar spine in thesupine, standing and sitting postures: characterization using an active shape modelJ. Anat. 2009; 215: 206211. 
[9] Youdas WJ, Tom RG, Soctt HJS, James RC. Lumbar lordosis and pelvic Inclination of Asymptomatic subjects. Physical Therapy. 1996; 76: 10.

[10] Noh YH, Keum DH. A clinical observation for the lumbosacral angle changes between initial and follow up treatment in low back pain patients. Journal of Oriental Rehabilitation Medicine. 2000; 10(1): 11-21.

[11] Sibani M, Ansuman R, Ardhendu, M, Sudeshna M, Abhik S, Sanjoy V. Sexual Dimorphism and Regional Difference in Size of Sacrum: A Study in Eastern India Al Ame en J Med Sci. 2 012; 5(3): 298 -307.

[12] Bogduk N. Clinical Anatomy of the lumbar spine and sacrum (4th Edition). USA: Elsevier Churchill Livingstone limited. 2005; 51-58.

[13] Monister M, Pettibon B, Schlappi H, Schloppe M, Ireland VR. Reflex Control of the Spine and Posture: A review of the literature from Chiropractic and osteopathy perpective. Chiropr Man Therap. 2005; 13: 16: 1746-1340.

[14] Peleg S, Gali Dar et al. Orientation of the Human sacrum: Anthropological perspective and methodological approaches. American Journal of Physical Anthropology. 2007; 133: 963-977.

[15] Korovesis P, Stamatakics M, Malkousis AG. Reciprocal angulation of vertebral bodies in the sagittal plane in an asymptomatic Greek population. Spine. 1998; (6): 704-705.

[16] Maclean JGB, Tucker JK, Latham JB. Radiographic appearances Wright J, Bell D. Lumbosacral joint angles in children. J. Paediatric. Orthp. 1991; 11(6): 748-751.

[17] Silva H. Sagittal Spine Lumbosacral Angles: view from a sample from Adolescents. Chilean Journal of Anatomy. $2001 ; 19(3): 1-13$.

[18] Cailliet CR. Low back pain Syndrome. (3rd ed.). Philadelphia: FA Davis Company. 1985: 11-21.

[19] Fadi AF, James M, Janowitz I. Stooped and Squatting Postures in the Workplace. ECP conference proceedings. Oakland, California, USA: July 29-30, 2004; 19-36.

[20] Nitin Patel. Surgical disorders of the thoracic and lumbar spine: a guide for neurologists. J neurolneurosurg psychiatry. 2002; 73:1(1): 142-8.

[21] Yochum TR. Rowe JL. Essential of Skeletal Radiology (3rd ed.). Philadelphia (USA): Williams and Wilkins. 2005; 217-220.

[22] Mescham R, Farrer MF. Synopsis of Radiologic Anatomy. 1975; 2: 332354.

[23] Portney LG, Watkins MP. Foundations of Clinical Research: Applications to Practice. 2nd ed. New Jersey. 2000; 23-37.

[24] Lehana T. Sample size determination in clinical trials. HRM 733 Class notes. 15.

[25] European Commission. Council Directive. Proposal for laying down basic safety standards for protection against the dangers arising from exposure to ionising radiation, 242 final 2011/0254 (NLE). 30.5.2012. Brussels

[26] Kyu-Bok K, Kim YJ, Muzaffar N, Jae-Hyuk Y, Kim YB, Eui-Dong Y. Changes of Sagittal Spinopelvic Parameters in Normal Koreans with Age over 50. Asian Spine Journal. 2010; 4(2): 96-101.

[27] Ananiadis C. The effect of scuba diving cylinder on static lumbar spine posture. [MSc]. Dissertation. Institute of technology, kwazulu Natal.

[28] Jonk LM. The influence of weight bearing on lumbar spine: A Radiological Study. South African journal of Radiology. 1964; 2(2): 25 -29.

[29] Kim HJ, Chung S, Kim S, Shin H, Lee J, Kim S, et al. Influences of trunk muscles on lumbar lordosis and sacral angle. Eur Spine J. 2006; 15: 409-14.

[30] Legaye J. The femoro-sacral posterior angle. Eur Spine J. 2007; 16: 219-225.

[31] Maduforo C, West O, Nwankwo N, Onwuchekwa R, Etawo US, Ogbulu D. Study of the Lumbosacral Angles of Males in Port Harcourt, South- South, Nigeria. The Nigerian Health Journal. 2012; 12(1): 22-24.

[32] Okpala FO. Measurement of Lumbosacral Angle in Normal Radiographs: A Retrospective Study in Southeast Nigeria. Annals of Medical and Health Sciences Research. 2014; 4(5): 757-762.

[33] Oyakhire OM, Didia BC. Metric analysis of the lumbosacral angle in a population of asymptomatic Nigerians. Afr. J. Med. Med. Sci. 2011; 4: 2141-2151. 
[34] Pietila TA, Stendel R, Kombos T, Ramsbacher J, Schulte T, Brock M. Lumbar disc herniation in patients up to 25 years of age. Neurologica Medico-Chirurfica(Tokyo). 2000; 41: 340-344.

[35] Odenigbo UM, Odenigbo UC, Oguejiofor OC, Adogu POU. Relationship of Waist Circumference, Waist Hip Ratio andBody Mass Index as Predictors of Obesity in Adult Nigerians Pakistan Journal of Nutrition. 2011; 10(1): 1518.

[36] Dhara S. Assessment of Anthropometric characteristics; Relationship with lumbar curvature among Santal community tribal children. International journal of applied research. 2015; 1(9): 972-976. 